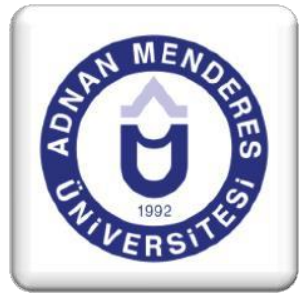

\section{ROC Analizi ile Zung Depresyon Ölçeği Kesme Noktalarının Belirlenmesi}

\author{
Erdi BAHADIR ${ }^{1}$, Bilal KALENDER ${ }^{2}$
}

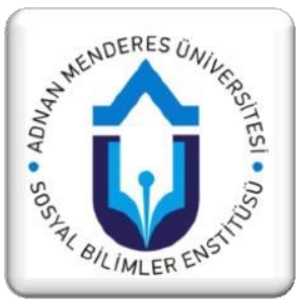

\title{
ÖZET
}

Zung Depresyon Ölçeği kliniklerde sıklıkla kullanılan bir tanı testidir. Klinik çalışmalarda hasta ve sağlıklı ayrımının yapılmasında, tanı testlerinin psikometrik özelliklerinin iyi olması gerekmektedir. Bu çalışmanın amacı ROC analizi kullanılarak Zung Depresyon Ölçeği'nin kadın ve erkek örneklem için kesme noktalarının bulunmasıdır. $\mathrm{Bu}$ amaçla yürütülen çalışmaya Haydarpaşa Numune Hastanesi ve Bezmialem Hastanesi'nde bulunan, depresyon tanısı almış 100 kişi ve herhangi bir psikolojik rahatsızlığı olmayan, sağlıklı 100 kişi olmak üzere 200 kişi katılmıştır. Katılımcılara demografik form ve Zung Depresyon Ölçeği'nin bulunduğu anket formu uygulanmıştır. Yapılan ROC analizi sonucunda erkek örneklem için 0,75 duyarlılık ve 0,97 özgüllü̈k değerlerinin bulunduğu 56 puan ve kadın örneklem için de 0,65 duyarlılık ve 0,95 özgüllük değerlerinin bulunduğu 52 puan kesme puanı olarak elde edilmiştir. ROC eğrisi altında kalan alan incelendiğinde erkek örneklem için bulunan 0,89 ve kadın örneklem için bulunan $0,86^{\prime}$ lık alanın istatistiksel olarak anlamlı olduğu görülmüștür. Hasta ve sağlıklı bireylerin depresyon puan ortalamalarının karşılaştırılmasında hasta bireylerin depresyon puanlarının anlamlı şekilde yüksek olduğu görülmüştür. Bu bulgular sonucunda Zung Depresyon Ölçeği'nin hasta-sağlıklı ayrımını iyi yapabildiği ve bu ayrımın yapılmasında kullanılacak kesme puanlarının psikometrik özelliklerinin yeterli olduğu görülmüştür.

Anahtar kelimeler: ROC analizi, Zung Depresyon Ölçeği, kesme puanı

\section{Determination of Zung Depression Scale Cut-off Points Using ROC Analysis}

\begin{abstract}
Zung Depression Scale is a frequently used diagnostic test in clinics. In clinical trials, the psychometric properties of diagnostic tests should be good for patient and healthy discrimination. The aim of this study is to find the cut points for male and female sample of Zung Depression Scale using ROC analysis. For this purpose, 200 people including with 100 people with depression diagnosis those whom stay in Haydarpaşa Numune Hospital and Bezmialem Hospital and 100 healthy people without any psychological disturbance participated. Questionnaire form containing demographic form and Zung Depression Scale were administered. As a result of the ROC analysis, 56 points for male sample with 0.75 sensitivity and 0.97 specificity and 52 points for female sample with 0.65 sensitivity and 0.95 specificity were obtained as the cut points. When the area under the ROC curve was examined, it was found that the area of 0.89 for the male sample and 0.86 for the female sample were statistically significant. Comparing the mean depression scores of patients and healthy subjects, it is seen that depression scores of the patients were significantly higher. As a result of these findings, it is seen that Zung Depression Scale can make good patient-healthy discrimination and the psychometric properties of the cut-off points to be used in making this discrimination are sufficient.
\end{abstract}

Key Words: $R O C$ analysis, Zung Depression Scale, cut point

\footnotetext{
${ }^{1}$ Psikolog, Fatih Sultan Mehmet Vakıf Üniversitesi Yüksek Lisans Öğrencisi, erdibhdr@gmail.com, İstanbul

${ }^{2}$ Psikolog, İstanbul Büyükşehir Belediyesi Halka İlişkiler Müdürlüğü , kalenderbilal@ gmail.com, İstanbul
} 


\section{Giris}

Psikolojide patolojileri doğru ve erken bir şekilde tanılamak önemlidir. Bu da tanı testi yardımı ile gerçekleşmektedir (Kanık ve Erdem, 2003). Tanı testleri özgün ölçme araçları ile patolojiyi değerlendirme sürecinin genel ismidir. Tanı testlerinin önemi daha sonralarda testlerin psikometrik özelliklerinin incelenmesini beraberinde getirmiştir. Tanı testlerinin ayırt edicilikleri için son yıllarda alan dizin çalışmalarında birçok yöntem kullanılmıştır. ROC (Reciever Operating Characteristic) analizi bunların içinde en yaygın olanıdır (Zou ve ark., 2007).

ROC analizinin tarihi 1940'lara kadar dayanmaktadır. II. Dünya Savaş1 sırasında İngiltere radar sinyallerinin doğru tespiti ve dost-düşman unsur ayrımının yapılması için bir algoritma geliştirmiştir (Dirican, 2001). Bu algoritma sayesinde doğru-yanlış ayrımını yapmak kolaylaşmıştır. Savunma sistemi amacıyla geliştirilen ROC analizi 1960'larda tıp alanında kullanılmaya başlamıştır. ROC analizi hastalık var-hastalık yok olasılıkları üzerinde temellenir (Kılıç, 2013). Kullanılan testin hasta-sağlıklı ayrımını ne kadar iyi yaptığı göstermek için kullanılır. ROC analizi için temel kavramlar Tablo1'de verilmiştir (Mason ve Graham, 2002).

Tablo 1. ROC Analizi Kuramsal Temeli

\begin{tabular}{|c|c|c|}
\hline & \multicolumn{2}{|c|}{ Gerçek Durum } \\
\hline Tanı Testi & Pozitif (Hasta) & Negatif (Sağlıkı) \\
\hline Pozitif (Hasta) & A (DP) & B (YP) \\
\hline Negatif (Sağlıkı) & C (YN) & D (DN) \\
\hline Toplam & A + C & B + D \\
\hline
\end{tabular}

Tabloda verilen:

A: gerçekte hasta olan ve tanı testi sonucunda hasta olarak değerlendirilen olguları (Doğru Pozitif, DP)

B: gerçekte sağlıklı olan ve tanı testi sonucunda hasta olarak değerlendirilen olguları (Yanlış Pozitif, YP)

C: gerçekte hasta olan ve tanı testi sonucunda sağlıklı olarak değerlendirilen olguları (Yanlış Negatif, YN)

D: gerçekte sağlıklı olan ve tanı testi sonucunda sağlıklı olarak değerlendirilen olguları (Doğru Negatif, DN) açıklamaktadır.

ROC analizi sonuçları iki değere bakılarak değerlendirilir. Bunlar:

Duyarlılık (Hassasiyet): gerçekte hasta olan olgular içinde tanı testinin hastaları ayırt etme gücünü gösterir (Dirican, 2001). Bu oranın yüksek olması tanı testinin gerçek hastaları bulma gücünü göstermiş olur. Duyarlılık formülü ise: A / A+C şeklindedir (K1lıç, 2013).

Seçicilik (Özgüllük): gerçekte sağlıklı olan olguların tanı testinden sağlıklı değerlendirmesini alma oranını temsil eder (Tomak ve Bek, 2011). Bu oranın yüksek olması tanı testinin sağl1klı olguları sağlıklı olarak ölçme gücünü gösterir. Seçicilik formülü ise: D / B+D şeklindedir (Weinstein ve ark., 2005). 


\subsection{ROC Ĕgrisi Altında Kalan Alan}

ROC eğrisi x ekseni (1-seçicilik) ve y ekseni (duyarlılık) üzerinde belirli eşik değerindeki noktaların oluşturduğu bir eğridir (Wagner ve ark., 2007). ROC eğrisi altında kalan alanın fazla olması tanı testinin iyi ölçümler yaptığının da göstergesidir (Metz, 2006). ROC eğrisi altında kalan alanlar şu şekilde yorumlanmaktadır (Hanley ve McNeal, 1983; Zou ve ark., 2007):

- $\quad 0.90-1.00=$ mükemmel

- $\quad 0.90-0.80=$ iyi

- $\quad 0.80-0.70=$ orta

- $\quad 0.70-0.60=$ zayif

- $\quad 0.60-0.50=$ kötü

\subsection{Zung Depresyon Ölçeği}

Zung Depresyon Ölçeği Zung (1965) tarafindan geliştirilen bir kendi bildirim ölçeğidir. Ölçek araştırmalarda sıklıkla kullanılmaktadır. Ayrıca organik temeli olmayan fiziksel şikayetlerle kendini belli eden "maskeli depresyonu" ortaya çıkarmakta başarılı sonuçlar vermektedir. Depresyonun duygusal, fizyolojik, psikomotor ve psikolojik boyutlarını ölçmektedir.

Ölçeğin Türk üniversite öğrencilerinde psikometrik özelliklerinin incelenmesi Gençdoğan (2001) tarafindan yapılmıştır. Buna göre benzer ölçekler geçerliği kapsamında ZDÖ ile Beck Depresyon Ölçeği (BDÖ) ve SCL- 90 Depresyon Alt Ölçeği arasındaki ilişkiler incelenmiştir. ZDÖ ile BDÖ arasında 0,89 ve SCL-90 DAÖ arasında ise 0,82 korelasyon belirlenmiştir. ZDÖ'nün iç tutarlık güvenirlik katsayısı sağlıklı üniversite öğrencileri için 0,80 ve hasta grubu için ise 0,84 olarak saptanmıştır (Doğan ve Çötok, 2011).

ZDÖ yurt dışında ülkemize oranla çok daha sık bir şekilde kullanılmaktadır. Yurt dışında farklı örneklemler üzerinde yapılmış geçerlik ve güvenirlik çalışmaları da mevcuttur. Zung Depresyon Ölçeği'nin Hamilton Depresyon Ölçeği, Beck Depresyon Ölçeği ve MMPI Depresyon Alt Ölçeği ile korelasyonu yüksek olduğu saptanmıştır. Yapılan diğer çalışmalarda Zung Depresyon Ölçeği' nin depresyonu diğer bozukluklardan ayırt edebildiği yani depresif olan kişilerle olmayan kişileri saptaya bildiği belirlenmiştir (Gençdoğan, 2001).

Zung Depresyon Ölçeği için güvenirlik ve geçerlik çalışmaları yapılsa da ölçeğin kesme puanları için mevcut bir çalışmaya rastlanmamıştır. Ceyhun ve Akça (1996) Zung' un sınıflandırma yüzdesi açısından verdiği 50 kesme puanını kullanmıştır. Bu çalışmada Zung Depresyon Ölçeği için hasta ve sağlıklı örneklem grupları kullanılarak kadın ve erkekler için kesme puanlarının bulunması amaçlanmıştır.

\section{Materyal ve Metot}

\subsection{Katılımcilar}

Yapılan çalışmaya Haydarpaşa Numune Hastanesi ve Bezmialem Hastanesi'nde yatarak ve ayakta tedavi gören ve yaşları 22-65 arasında değişen $(\overline{\mathrm{x}}=35,20 \pm 10,81)$ depresyon tanılı 100 
kişi ve basit tesadüfi örnekleme yolu ile seçilen daha önce herhangi bir psikolojik rahatsızlığ olmamış şu anda da psikolojik sorunları bulunmayan yaşları 18-69 arasındaki $(\overline{\mathrm{x}}=37,27 \pm 12,98) 100$ kişi olmak üzere toplam 200 kişi katılmıştır. Katılımcılar gönüllülük esasına uygun olarak çalışmada yer almıştır.

\section{2. Ölçme Araçları}

Yapılan çalışmada demografik form ve Zung Depresyon Ölçeği kullanılmıştır.

Demografik form: araştırmacı tarafından oluşturulan katılımcıların yaş, cinsiyet, eğitim ve medeni durumlarını içeren soruların olduğu formdur.

Zung Depresyon Ölçeği: Zung (1965) tarafından geliştirilen ve 10'u olumlu 10'u olumsuz olmak üzere 20 sorudan oluşan bir kendi bildirim ölçeğidir. Ölçek maddeleri 1-4 puan arasında puanlanmaktadır. $2,5,6,11,12,14,16,17,18$. ve 20 . maddeler ters yönlü maddelerdir. Türkçe güvenirlik ve geçerlik çalışması Gençdoğan (2001) tarafindan yapılmıştır. Türk örneklemde hasta grup için 0,84 ve sağlıklı grup için 0,80 güvenirlik katsayısı bulunmuştur. Bu çalışmada sağlıklı grup için 0,78 ve hasta grup için 0,94 'lük Cronbach Alfa katsayısı bulunmuştur.

\section{3. İșlem}

Katılımcılara demografik form ve Zung Depresyon Ölçeğinin bulunduğu anket formu verilmiş ve doldurmaları istenmiştir. Anketin doldurulması ortalama beş dakika sürmüş. Elde edilen bilgiler tasnif edilip bilgisayar ortamına aktarılmıştır.

\section{4. İstatistiksel Analiz}

Verilerin analizinde SPSS.24 (Statistical Package For The Social Sciences) ve MedCalc.14 paket programı kullanılmıştır. Çalışmada tanımlayıcı istatistikler, ki-kare bağımsızlık testi, bağımsız örneklem $\mathrm{t}$ testi ve ROC analizi kullanılmıştır.

\section{Bulgular}

$\mathrm{Bu}$ bölümde analiz sonuçları incelenmekte olup elde edilen bulgular $\mathrm{p}=0,01$ ve $\mathrm{p}=0,001$ anlamlılık derecesinde yorumlanmıştır. 
Tablo 2. Demografik Değişkenlerin Sayı ve Yüzde Dağılımı

\begin{tabular}{|c|c|c|c|c|c|c|}
\hline \multicolumn{3}{|c|}{ Değişkenler } & \multirow{2}{*}{$\begin{array}{r}\begin{array}{c}\text { Sağlıklı } \\
\text { Grup }\end{array} \\
40 \\
\end{array}$} & \multirow{2}{*}{$\begin{array}{r}\begin{array}{c}\text { Hasta } \\
\text { Grup }\end{array} \\
40 \\
\end{array}$} & \multirow[t]{2}{*}{$\chi^{2}$} & \multirow[t]{2}{*}{$\mathbf{p}$} \\
\hline \multirow{6}{*}{ Cinsiyet } & \multirow{3}{*}{ Erkek } & Kişi sayıs1 & & & & \\
\hline & & Satır yüzdesi & $\% 50$ & $\% 50$ & \multirow{5}{*}{1,00} & \multirow{5}{*}{0,557} \\
\hline & & Sütun yüzdesi & $\% 40$ & $\% 40$ & & \\
\hline & \multirow{3}{*}{ Kadın } & Kişi sayısı & 60 & 60 & & \\
\hline & & Satır yüzdesi & $\% 50$ & $\% 50$ & & \\
\hline & & Sütun yüzdesi & $\% 60$ & $\% 60$ & & \\
\hline \multirow{9}{*}{ Medeni durum } & \multirow{3}{*}{ Evli } & Kişi sayısı & 40 & 53 & \multirow{9}{*}{3,43} & \multirow{9}{*}{0,180} \\
\hline & & Satır yüzdesi & $\% 43$ & $\% 57$ & & \\
\hline & & Sütun yüzdesi & $\% 40$ & $\% 53$ & & \\
\hline & \multirow{3}{*}{ Bekar } & Kişi sayısı & 45 & 36 & & \\
\hline & & Satır yüzdesi & $\% 55,6$ & $\% 44,4$ & & \\
\hline & & Sütun yüzdesi & $\% 45$ & $\% 36$ & & \\
\hline & \multirow{3}{*}{ Boşanmış } & Kişi sayısı & 15 & 11 & & \\
\hline & & Satır yüzdesi & $\% 57,7$ & $\% 42,3$ & & \\
\hline & & Sütun yüzdesi & $\% 15$ & $\% 11$ & & \\
\hline \multirow{9}{*}{$\begin{array}{l}\text { Eğitim } \\
\text { durumu }\end{array}$} & \multirow{3}{*}{ İlkokul } & Kişi sayısı & 15 & 29 & \multirow{9}{*}{10,72} & \multirow{9}{*}{0,005} \\
\hline & & Satır yüzdesi & $\% 34,1$ & $\% 65,9$ & & \\
\hline & & Sütun yüzdesi & $\% 15$ & $\% 29$ & & \\
\hline & \multirow{3}{*}{ Lise } & Kişi sayısı & 28 & 36 & & \\
\hline & & Satır yüzdesi & $\% 43,8$ & $\% 56,3$ & & \\
\hline & & Sütun yüzdesi & $\% 28$ & $\% 36$ & & \\
\hline & \multirow{3}{*}{ Üniversite } & Kişi sayısı & 57 & 35 & & \\
\hline & & Satır yüzdesi & $\% 62$ & $\% 38$ & & \\
\hline & & Sütun yüzdesi & $\% 57$ & $\% 35$ & & \\
\hline \multicolumn{3}{|l|}{ Toplam } & 100 & 100 & & \\
\hline
\end{tabular}

Yapılan çalışmada sağlıklı grup için 40 erkek ve 60 kadın; hasta grup için 40 erkek 60 kadın bulunmaktadır. Sağlıklı grup için 40 kişi evli, 45 kişi bekar ve 15 kişi boşanmıştır. Hasta grup için ise 53 kişi evli, 36 kişi bekar ve 11 kişi boşanmıştır. Sağlıklı gruptaki 100 kişiden 15'i ilkokul, 28'i lise ve 57'si üniversite mezunudur. Hasta grup için 29 kişi ilkokul, 36 kişi lise ve 35 kişi üniversite mezunudur. Demografik değişkenlerin hasta-sağlıklı gruba dağılımları için cinsiyet ve medeni durum değişkenleri için anlamlı farklılık bulunmazken $(p>0,05)$ eğitim durumu değişkeni için anlamlı farklılık bulunmuştur $\left(\chi_{(2)}^{2}=10,72 ; p<0,01\right)$. 

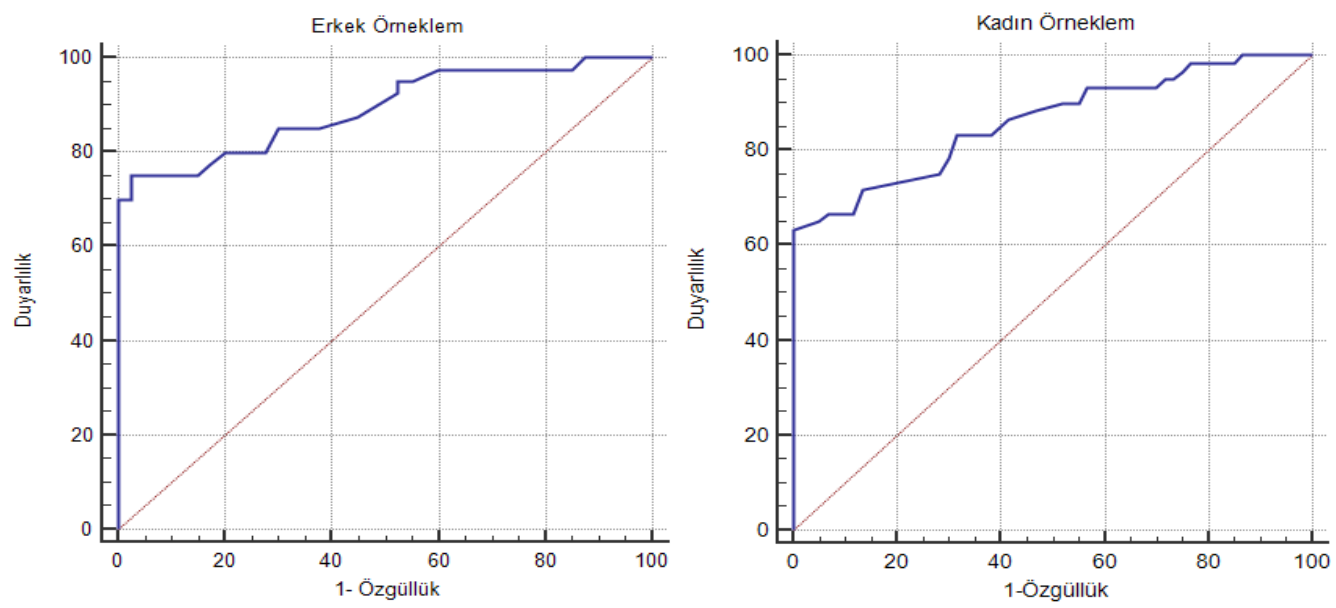

Şekil 1. Erkek ve Kadın Örneklem için Zung Depresyon Ölçeği ROC Eğrisi

Kesme puanının bulunması için yapılan ROC analizinde erkek örneklemde kesme puanının 56 olduğu görülmüştür. Duyarlılık için 0,75 ve özgüllük için 0,97 değerleri elde edilmiştir. Ayrıca ROC eğrisi altında kalan alan istatistiksel olarak anlamlıdır ve 0,89 olarak bulunmuştur $(\mathrm{z}=10,66 ; \mathrm{p}<0,001)$. Kadın örneklem için ise kesme puanı 52 olarak gözlenmiştir. Duyarlılık değeri 0,65 ve özgüllük değeri de 0,95 'tir. ROC eğrisi altında kalan $0,86^{\prime}$ lık alan istatistiksel olarak anlamlı bulunmuştur $(\mathrm{z}=10,74 ; \mathrm{p}<0,001)$.

Tablo 3. Elde Edilen Kesme Puanlarına Göre Duyarlılık ve Özgüllük Değerleri

\begin{tabular}{|c|c|c|c|c|c|}
\hline \multirow{2}{*}{ Kesme Puanı } & \multicolumn{2}{|c|}{ Erkek Örneklem } & \multirow{2}{*}{ Kesme Puanı } & \multicolumn{2}{|c|}{ Kadın Örneklem } \\
\cline { 2 - 3 } & Duyarlıl1k & Özgüllük & & Duyarlılık & Özgüllük \\
\hline$>46$ & 0,87 & 0,55 & $>42$ & 0,86 & 0,58 \\
\hline$>47$ & 0,85 & 0,62 & $>43$ & 0,85 & 0,60 \\
\hline$>49$ & 0,85 & 0,70 & $>44$ & 0,83 & 0,61 \\
\hline$>50$ & 0,80 & 0,72 & $>46$ & 0,83 & 0,68 \\
\hline$>52$ & 0,80 & 0,80 & $>47$ & 0,78 & 0,70 \\
\hline$>53$ & 0,77 & 0,82 & $>48$ & 0,75 & 0,71 \\
\hline$>54$ & 0,75 & 0,85 & $>49$ & 0,71 & 0,86 \\
\hline$>56^{*}$ & 0,75 & 0,97 & $>50$ & 0,66 & 0,88 \\
\hline$>57$ & 0,70 & 0,97 & $>51$ & 0,66 & 0,93 \\
\hline$>58$ & 0,70 & 100 & $>52^{*}$ & 0,65 & 0,95 \\
\hline
\end{tabular}

Erkek ve kadın örneklem için yapılan ROC analizleri sonucunda kesme puanlarına ait duyarlılık ve özgüllük değerleri Tablo 3'te verilmiştir. Her iki örneklem için de MedCalc.14 paket programının analiz sonunda verdiği kesme puanları seçilmiştir. 
Tablo 4. Erkek ve Kadın Örneklem Ị̧̇in Bulunan Kesme Noktasına Göre Karışıklık Matrisi

\begin{tabular}{|c|c|c|c|c|c|}
\hline \multicolumn{2}{|c|}{ Erkek Örneklem } & \multicolumn{2}{c|}{ Kadın Örneklem } \\
\hline Tanı Testi & Gerçek Durum & \multicolumn{2}{c|}{ Gerçek Durum } \\
\hline Hasta & 30 & Sağlıklı & Tanı Testi & Hasta & Sağlıkı \\
\hline Sağlıklı & 10 & 1 & Hasta & 39 & 3 \\
\hline
\end{tabular}

Kadın ve erkek örneklem için bulunan kesme noktalarına göre gerçek durum ve tanı testi sonuçlarının dağılımı tablo 4'te verilmiştir. Depresyon puanı için bağımsız grupların karşılaştırılmasında normallik varsayımının sağlandığı görülmüş ve parametrik testlerin kullanılmasına karar verilmiştir. Hasta grubu için demografik bilgilere göre depresyon puanlarının karşılaştırılması yapılmıştır.

Tablo 5. Demografik Bilgilere Göre Hasta Grubun Zung Depresyon Ölçeği Puan Ortalamalarının Karşılaş̧tırılması

\begin{tabular}{|c|c|c|c|c|c|c|c|}
\hline \multicolumn{2}{|c|}{ Değişken } & $\mathbf{n}$ & $\overline{\mathbf{x}}$ & ss & $t / F$ & s.d & $\mathbf{p}$ \\
\hline \multirow[t]{2}{*}{ Cinsiyet } & Erkek & 40 & 67,77 & 13,80 & \multirow{2}{*}{1,98} & \multirow{2}{*}{98} & \multirow{2}{*}{0,032} \\
\hline & Kadın & 60 & 62,05 & 14,94 & & & \\
\hline \multirow[t]{3}{*}{ Medeni durum } & Evli & 53 & 67,72 & 13,62 & \multirow{3}{*}{3,83} & \multirow{3}{*}{ 2/97 } & \multirow{3}{*}{0,024} \\
\hline & Bekar & 36 & 59,14 & 14,96 & & & \\
\hline & Boşanmış & 11 & 64,64 & 14,96 & & & \\
\hline \multirow[t]{3}{*}{ Eğitim durumu } & İlkokul & 29 & 73,21 & 8,80 & \multirow{3}{*}{8,72} & \multirow{3}{*}{ 2/97 } & \multirow{3}{*}{0,000} \\
\hline & Lise & 36 & 60,64 & 15,80 & & & \\
\hline & Üniversite & 35 & 60,66 & 14,50 & & & \\
\hline
\end{tabular}

Yapılan analizlerde Levene varyans homojenliği testi sonucunda varyansların homojen olduğu görülmüştür. Bağımsız örneklem $t$ testi ve varyans analizi sonuçlarına göre katılımcıların depresyon puan ortalamalarının demografik bilgilere göre farklılaştığ görülmüştür. Cinsiyete göre erkeklerin $(\overline{\mathrm{x}}=67,77)$, medeni duruma göre evlilerin $(\overline{\mathrm{x}}=67,72)$ ve eğitim durumuna göre ilkokul mezunu olanların $(\overline{\mathrm{x}}=73,21)$ depresyon puan ortalamaları anlamlı şekilde yüksek bulunmuştur.

Tablo 6. Hasta ve Sağılıkı Grup İçin Zung Depresyon Ölçeği Puan Ortalamalarının Karşılaştırılması

\begin{tabular}{|l|c|c|c|c|c|c|}
\hline \multicolumn{1}{|c|}{ Grup } & n & $\overline{\mathbf{x}}$ & ss & t & s.d & p \\
\hline Hasta grup & 100 & 64,29 & 14,67 & \multirow{2}{*}{13,16} & \multirow{2}{*}{198} & \multirow{2}{*}{0,000} \\
\cline { 1 - 5 } Sağlıklı grup & 100 & 41,72 & 8,88 & & & \\
\hline
\end{tabular}

Hasta ve sağlıklı gruptaki katılımcıların depresyon puanları arasında istatistiksel olarak anlamlı farkl11ık bulunmuştur $\left(\mathrm{t}_{(198)}=13,16 ; \mathrm{p}<0,001\right)$. Hasta gruptaki katılımcıların depresyon puan ortalamalarının sağlıklı gruptaki katılımcılardan yüksek olduğu görülmüştür. 


\section{Tartışma}

Zung Depresyon Ölçeği depresyonun ölçülmesinde ve tanı konulmasında klinik ortamda ve akademik çalışmalarda sıklıkla kullanılan bir ölçektir. Alan dizin çalışmaları incelendiğinde Zung Depresyon Ölçeği'nin psikometrik özelliklerini inceleyen çok az çalışma bulunmaktadır. Ölçeğin Türkçe güvenirlik ve geçerlilik çalışması Ceyhun ve Akçay (1996) tarafından yapılmış ve ölçeğin psikometrik özellikleri incelenmiştir. Ancak bu çalışmada kesme puanları bulunmamış, Zung tarafından önerilen 50 kesme puanı kullanılmıştır. Gençdoğan (2001) ölçeğin lise ve üniversite öğrencilerindeki güvenirlik, geçerlilik ve faktör yapısını incelemiştir. Ancak bu çalışmada da ölçek için kesme puanları incelenmemiştir. Alan dizin çalışmalarında görülen bu eksiklikler sonucunda bu çalışmada Zung Depresyon Ölçeği için kadın ve erkek örneklem için kesme puanlarının bulunması amaçlanmıştır. Bu amaçla kesme puanlarının incelenmesinde sıklıkla kullanılan ROC analizi kullanılmıştır.

Bulgular kısmındaki, ROC analizi sonucunda erkek örneklemi için kesme puanı 56 ve kadın örneklem için ise 52 olarak bulunmuştur. Alan dizin çalışmaları incelendiğinde çeşitli alanlarda kadın ve erkekler için ROC analizi sonucunda farklı kesme noktalarının verildiği görülmüştür (Karakaya, 2011; Moraes ve ark., 2009). Elde edilen kesme puanlarının duyarlılık ve özgüllük değerlerinin hasta-sağlıklı ayrımını yapmada iyi olduğu ve psikometrik özelliklerinin yeterli olduğu görülmüştür. Ayrıca ROC eğrisi altında kalan alanların 0,89 ve 0,86 olduğu görülmüsstür. Hasta ve sağlıklı katılımcıların depresyon puan ortalamaları arasında istatistiksel olarak anlamlı farklılık bulunmuştur. Hasta katılımcıların depresyon puan ortalaması yüksek bulunmuştur. Bulgular 1şığında Zung Depresyon Ölçeği'nin depresyonu ölçmede ve hasta-sağlıklı ayrımını yapmada başarılı bir ölçme aracı olduğu görülmüştür. Kadın ve erkek örneklem için elde edilen kesme noktalarına göre yapılan karışıklık matrisinde gerçek durumda hasta olan kişilere hasta (doğru pozitif) ve gerçek durumda sağlıklı olan kişilere sağliklı (doğru negatif) tanısı koymada yüksek yüzdeler bulunmuştur.

\section{Sonuç}

$\mathrm{Bu}$ çalışma sonucunda kadın ve erkeklerin depresyon için kırılganlıkları ve cinsiyete göre depresyonun sıklığı göz önüne alınarak hem kadın hem de erkek örneklemleri için Zung Depresyon Ölçeği kesme puanları bulunmuştur. Ayrıca hasta grubu için kadın ve erkeklerin depresyon puan ortalamaları arasındaki farklılık kadın ve erkek için ayrı kesme noktalarının bulunması gerektiğini göstermiştir. Elde edilen bu kesme puanları klinik ortamlarda tanı koymada kolaylık sağlamanın yanında akademik çalışmalarda da araştırmacılara hastasağlıklı ayrımını yapmada kolaylıklar sunacaktır. 


\section{KAYNAKÇA}

CEYHUN, B., \& AKÇA, F. (1996). Zung Depresyon Ölçeğinin Geçerlik Ve Güvenirliği Üzerine Bir Çalışma. VIII. Ulusal Psikoloji Kongresi Bilimsel Çalışmaları, Türk Psikologlar Derneği Yayınları, 20-26.

DIRİCAN, A. (2001). Evaluation Of The Diagnostic Test's Performance And Their Comparisons. Cerrahpaşa J Med, 32(1), 25-30.

DOĞAN, T., \& ÇÖTOK, N. (2011). Oxford Mutluluk Ölçeğinin Kısa Formunun Türkçe Uyarlaması: Geçerlik Ve Güvenirlik Çalışması. Türk Psikolojik Danışma Ve Rehberlik Servisi, 4(36), 165-172.

GENÇDOĞAN, B. (2001). Zung Depresyon Ölçeğinin Lise Öğrencileri İçin Geçerlik Ve Güvenirliği. Doktora Tezi. Atatürk Üniversitesi, Sosyal Bilimler Enstitüsü, Erzurum.

HANLEY, J. A., \& MCNEIL, B. J. (1983). A Method Of Comparing The Areas Under Receiver Operating Characteristic Curves Derived From The Same Cases. Radiology, 148(3), 839-843.

KANIK E.A., \& ERDEN S. (2003). Tanı Testlerinin Değerlendirilmesinde ROC (Receive Operating Characteristics) Eğrisinin Kullanımı. Mersin Üniversitesi Tıp Fakültesi Dergisi, 3, 260-268.

KARAKAYA, J. (2011). Üç Yönlü ROC Analizi Ve Ortak Değişken Düzeltmesi. Doktora Tezi, Hacettepe Üniversitesi, Sağl1k Bilimleri Enstitüsü, Ankara.

KILIÇ, S. (2013). Klinik Karar Vermede ROC Analizi. Journal Of Mood Disorders, 3(3), $135-140$.

MASON, S. J., \& GRAHAM, N. E. (2002). Areas Beneath The Relative Operating Characteristics (ROC) And Relative Operating Levels (ROL) Curves: Statistical Significance And İnterpretation. Quarterly Journal Of The Royal Meteorological Society, 128(584), 2145-2166.

METZ, C. E. (2006). Receiver Operating Characteristic Analysis: A Tool For The Quantitative Evaluation Of Observer Performance And İmaging Systems. Journal Of The American College Of Radiology, 3(6), 413-422.

MORAES, S.A., FREITAS, I.C.M., MONDINİ, L., \& ROSAS, J.B. (2009). Receiver Operating Characteristic (ROC) Curves To İdentify Birth Weight Cutoffs To Predict Overweight İn Mexican School Children. Journal De Pediatria, 85(1), 42-48.

TOMAK, L. Ve BEK, Y. (2011). İşlem Karakteristik Eğrisi Analizi Ve Eğri Altında Kalan Alanların Karşılaştırılması. Journal Of Experimental And Clinical Medicine, 27(2), 28-35.

WAGNER, R. F., METZ, C. E. \& CAMPBELL, G. (2007). Assessment Of Medical İmaging Systems And Computer Aids: A Tutorial Review. Academic Radiology, 14(6), 723748 .

WEINSTEIN, S., OBUCHOWSKİ, N. A. And LIEBBER, M. L. (2005). Clinical Evaluation Of Diagnostic Tests. American Journal Of Roentgenology, 184(1), 14-19.

ZOU, K. H., O'MALLEY, A. J. \& MAURİ, L. (2007). Receiver-Operating Characteristic Analysis For Evaluating Diagnostic Tests And Predictive Models. Circulation, 115(5), 654-657. 
Adnan Menderes Üniversitesi, Sosyal Bilimler Enstitüsü Dergisi, Cilt: 5, Sayı: 2(Sf. 137 - 147) Adnan Menderes University, Journal of Institute of Social Sciences, Vol.:5, No: 2 (pp. 137 - 147)

ZUNG, W.W. (1965). A Self-Rating Depression Scale. Archives Of General Psychiatry, $12(1), 63-70$. 


\section{EKLER}

\section{Zung Depresyon Ölçeği}

\begin{tabular}{|c|c|c|c|c|}
\hline $\begin{array}{l}\text { Aşağıda davranışlarınız ve hislerinizle ilgili ifadeler yer } \\
\text { almaktadır. Lütfen geçen hafta boyunca aşağıdakileri ne } \\
\text { sıklıkla hissettiğinizi ve yaşadığınızı belirtin. }\end{array}$ & 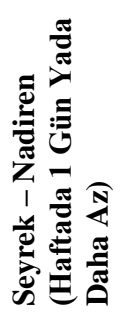 & 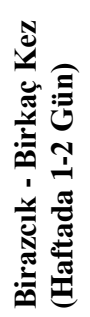 & 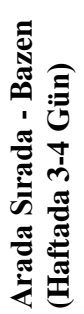 & 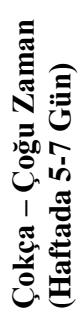 \\
\hline 1. Kendimi üzgün ve mutsuz hissediyorum. & $\square$ & $\square$ & $\square$ & $\square$ \\
\hline 2. Sabahları kendimi en iyi hissettiğim zamanlardır. & $\square$ & $\square$ & $\square$ & $\square$ \\
\hline 3. Ağlama nöbetlerim var ya da öğle hissediyorum. & $\square$ & $\square$ & $\square$ & $\square$ \\
\hline 4. Geceleri uyamiyorum. & $\square$ & $\square$ & $\square$ & $\square$ \\
\hline 5. Eskiden olduğu kadar yiyorum. & $\square$ & $\square$ & $\square$ & $\square$ \\
\hline 6. Hala seksten zevk aliyorum. & $\square$ & $\square$ & $\square$ & $\square$ \\
\hline 7. Kilo vermeye başladığımı fark ettim. & $\square$ & $\square$ & $\square$ & $\square$ \\
\hline 8. Kabızlık çekiyorum. & $\square$ & $\square$ & $\square$ & $\square$ \\
\hline 9. Kalp atışlarım normalden daha hızlı/çarpıntım var. & $\square$ & $\square$ & $\square$ & $\square$ \\
\hline 10. Hiçbir sebep olmaksızın yoruluyorum. & $\square$ & $\square$ & $\square$ & $\square$ \\
\hline 11. Zihnim karışık/bulanık değil. & $\square$ & $\square$ & $\square$ & $\square$ \\
\hline 12. Her zamanki gibi yaptığım işler bana kolay geliyor. & $\square$ & $\square$ & $\square$ & $\square$ \\
\hline 13. Huzursuzum ve yerimde duramıyorum. & $\square$ & $\square$ & $\square$ & $\square$ \\
\hline 14. Geleceğe umutla bakıyorum. & $\square$ & $\square$ & $\square$ & $\square$ \\
\hline 15. Normalde olduğumdan daha alınganım. & $\square$ & $\square$ & $\square$ & $\square$ \\
\hline 16. Karar vermekte zorlanmiyorum. & $\square$ & $\square$ & $\square$ & $\square$ \\
\hline 17. Yararlı olduğumu ve bana ihtiyaç duyulduğunu hissediyorum. & $\square$ & $\square$ & $\square$ & $\square$ \\
\hline 18. Hayatım dopdolu. & $\square$ & $\square$ & $\square$ & $\square$ \\
\hline 19. Eğer ölsem, diğerlerinin daha iyi olacaklarını hissediyorum. & $\square$ & $\square$ & $\square$ & $\square$ \\
\hline 20. Eskiden yapmaktan hoşlandığım şeyler hala hoşuma gidiyor. & $\square$ & $\square$ & $\square$ & $\square$ \\
\hline
\end{tabular}

